\title{
LO HUMANO COMO VALOR EPISTÉMICO. APUNTES EN TORNO A LA OBRA TARDÍA DE PAUL KARL FEYERABEND
}

\author{
The humane as epistemic value. \\ Considerations with respect to the late work of Paul Karl Feyerabend
}

\author{
Teresa Gargiulo*
}

\section{RESUMEN}

El pensamiento de Feyerabend ha sido objeto de múltiples y divergentes interpretaciones. Pero entre ellas parece ser unánime la inscripción de su obra dentro de las coordenadas de un escepticismo radical. Ahora bien dicha crítica no solo no ha comprendido la verdadera naturaleza de su anarquismo epistemológico sino que tampoco ha sabido entender la propuesta positiva de ciencia que hace el vienés. Nuestro propósito es exponer una de las dimensiones fundamentales de este modelo de ciencia alternativo. Lo humano entendiendo por tal el contenido vivencial de una teoría o cultura- se erige para Feyerabend como el valor o criterio según el cual debe evaluarse la supuesta superioridad de la ciencia frente a otras tradiciones de pensamiento.

Palabras clave: Feyerabend, Aristóteles, ciencia, cultura, ciencia humana.

\begin{abstract}
The Feyerabend's thought has been object of multiple and divergent interpretations. But among them seems to be unanimous the inscription of his work within the coordinates of a radical skepticism. Now such criticism not only has not understood the real nature

* Instituto de Filosofía, Universidad Nacional de Cuyo. Mendoza, Argentina. Correo electrónico: gargiulomteresa@yahoo.com.ar

Artículo recibido el 11 de abril de 2014. Aceptado el 22 de octubre de 2014.
\end{abstract}


of his epistemological anarchism but also it has not been able to understand the positive proposal of science that the Viennese does. Our intention is to expose one of the fundamental dimensions of this alternative model of science. The human -understood as the experiential content of a theory or culture- it is raised for Feyerabend as the value or criterion according to which the supposed superiority of the science must be evaluated opposite to other traditions of thought.

Keywords: Feyerabend, Aristotle, science, culture, human science.

\section{INTRODUCCIÓN}

No han faltado críticos que acusen a Feyerabend de abanderar un escepticismo por el cual se tornaría incapaz de ofrecer una explicación de la ciencia alternativa a las que rechaza. Hooker afirma:

Feyerabend ha subrayado [que] el uso de una reductio ad absurdum no es un compromiso a creer en sus premisas. Entonces, no puedo condenar los presupuestos formalistas tácitos de Feyerabend simplemente observando la crudeza de sus formulaciones. Pero entonces la gente razonable tiene el derecho a pedir una explicación positiva que sustituya aquello que ha sido rechazado. El hecho mismo que Feyerabend no ofrezca ninguna, y que lo que él realmente ofrece permanece dentro de las formulaciones ordinarias empleadas en sus propias reducciones, sugiere que él de hecho está limitado por sus presuposiciones tácitas (Hooker, 1991: 96).

Preston en Science as Supermarket: 'Post-Modern' Themes in PaulFeyerabend's Later Philosophy of Science (2000) sostiene que las últimas obras de Feyerabend se inscriben dentro de las coordenadas de una filosofía deconstructiva en el sentido de Derrida. Pues en ellas lejos de proponer una teoría o una comprensión positiva de la ciencia, se limita a criticar o desestabilizar lo modelos científicos que ofrecen sus interlocutores. Feyerabend -según Preston- no está interesado en elucidar la ciencia sino en destruirla:

El filósofo posmoderno no tiene interés en 'esclarecer' la ciencia. [...] Las últimas obras de Feyerabend, me parece, se ajustan a esta descripción bastante bien. Nunca se interesó por 'aclarar' o simplemente explicar las actividades de los agentes de primer orden. En sus obras anteriores, su objetivo declarado era el de introducir el progreso científico dentro de la filosofía. En su posterior encarnación, como es bien sabido, entierra esta concepción científica de la filosofía (aunque nunca desaparece totalmente), y es enterrada debajo de una cosmovisión postmoderna (Preston, 2000: 88-89). 
Neto arguye que el anarquismo de Feyerabend es análogo al escepticismo de los antiguos griegos puesto que mediante este él puede argumentar a favor de cualquier posición (Neto, 1991). Musgrave asegura que el anarquismo epistemológico de Feyerabend supone "la tesis que cualquier teoría o programa de investigación es tan bueno como cualquier otro” (Musgrave, 1978: 192). Luego parecería que según su anarquismo epistemológico no hay nada que pueda ser llamado ciencia, o lo que es lo mismo, que todo puede ser reconocido como científico.

En pocas palabras, los críticos presentan habitualmente a Feyerabend como un escéptico erudito, como un irracionalista que arremete contra la ciencia. Muchas de estas acusaciones encuentran sustento en el desconocimiento de su estilo dialéctico, de su recurso a la ironía y de su frecuente uso de los razonamientos por reducción al absurdo. Particularmente el desconocimiento de su recurrente uso de este último recurso lógico ha promovido que frecuentemente sus críticos le adjudiquen un compromiso o una defensa positiva de las inferencias absurdas que no son sino para él consecuencias lógicas que se siguen de las premisas de sus interlocutores, tales como el irracionalismo, el anarquismo o el relativismo.

Estas interpretaciones parecen no haber comprendido la verdadera naturaleza del anarquismo epistemológico que Feyerabend formula en los ańos 70, en la medida que aquel no representa su concepción acerca de la ciencia. Su anarquismo epistemológico no es sino reducción al absurdo de los intentos del positivismo lógico y del racionalismo crítico por definir axiomática o metodológicamente a la ciencia. En La Ciencia en una Sociedad Libre el vienés escribe: "'todo vale” no expresa ninguna convicción mía, sino que es un compendio jocoso de los apuros del racionalista" (Feyerabend, 1978/1982: 223) ${ }^{1}$. A través de su anarquismo el vienés busca demostrar que si se aceptan las interpretaciones tradicionales de la ciencia se debe reconocer que los episodios más significativos de la historia de la ciencia son irracionales. Mas esto no supone que conciba positivamente a la ciencia como una empresa irracional. Lo que quiere mostrar es que la ciencia presenta este atributo en la medida que se intenta comprender el quehacer científico bajo los cánones tradicionales de los filósofos de la ciencia.

$\mathrm{El}$ anarquismo epistemológico constituye en sí mismo una reducción al absurdo de los intentos del positivismo lógico y del racionalismo crítico por definir axiomática o metodológicamente la ciencia y, en este sentido, puede ser entendido como una argumentación negativa y escéptica respecto a aquellas nociones de

\footnotetext{
${ }^{1}$ Para facilitar la lectura, las citas de las obras de Paul Feyerabend tendrán doble fecha. La primera se refiere al año de la primera publicación y la segunda a la publicación consultada. El objetivo de la doble fecha es dar cuenta de un orden cronológico de las publicaciones y, al mismo tiempo, remitir al lector a los lugares precisos donde pueda cotejar las citas textuales, las paráfrasis y las referencias generales.
} 
ciencia. No obstante, esto no implica que Feyerabend no haya desarrollado a través de esta crítica una noción positiva de ciencia.

Si los estándares del positivismo lógico, los programas de investigación de Lakatos o las revoluciones científicas de Thomas Kuhn no pueden, según Feyerabend, explicar los episodios de la ciencia, ello da cuenta no solo de la pobreza de sus definiciones de ciencia sino también de la necesidad de esbozar una noción de ciencia que subsuma la complejidad y riqueza del quehacer científico. En un sentido positivo se puede decir que Feyerabend mostró la necesidad de esbozar una explicación más compleja del conocimiento científico que la que ofrece el racionalismo crítico y el positivismo lógico.

Pero Feyerabend nunca pretendió elaborar una filosofía a modo de un sistema abstracto que establezca una respuesta conclusiva, universal y necesaria acerca de la ciencia, la sociedad, la cultura y el mito. Por el contrario, insiste en numerosos pasajes que su obra sea leída como un ensayo periodístico mas nunca como un sistema filosófico (Cf. Feyerabend 1975/1992: 16-17, 102; 1978/1982: 191; 1978/1993: 148-149; 1989/2000: 151, 156-157, 159; 1991a: 149, 153-154, 155; 1991c: 487; 1991/2003: 182; 1996/1999: 136; 1994/2000: 162-163). Dicha insistencia manifiesta su reticencia a formular un nuevo modelo prescriptivo de ciencia que repita los parámetros y cánones universales propios del racionalismo científico $^{2}$. Pero esto, no implica que no haya esbozado aunque de un modo noracionalista algunas respuestas positivas a las cuestiones que se planteó a lo largo de su vida.

En 1977 bajo el título Solicitud de un Año Sabático, Feyerabend ofrece importantes claves para entender su obra. Allí explica que después de la reducción al absurdo de los distintos criterios de demarcación lo que resta es la tarea caracterizada como un plan a largo plazo- de formular una nueva teoría o modelo de ciencia:

Resultado: ni el contenido, ni el método, ni las reglas de la razón nos autorizan a separar la ciencia de la no-ciencia. Toda separación producida es un fenómeno local; se produce bajo ciertas condiciones, entre ciertas partes de la ciencia y ciertas partes de la no-ciencia, y no pueden utilizarse para inferir una diferencia esencial entre las cosas separadas.

\footnotetext{
${ }^{2}$ Entre los errores recurrentes del racionalismo que él dice tener especial cuidado de evitar mencionar: las síntesis fáciles por las que se establece un efecto uniforme de causas independientes y fortuitas; el racionalismo forzoso por el cual se presenta como razonables aquellos estándares que son conforme a las últimas tendencias sociales; la trasferencia de categorías actuales al pasado; la generalización de casos individuales; el reduccionismo de los cambios intelectuales a tendencias sociológicas o a hipótesis intelectualistas (Cf. Feyerabend 1977/2013: 307-308).
} 
Plan a largo plazo

Mi plan a largo plazo es construir una teoría del conocimiento que tenga en cuenta esta situación. Esta teoría diferirá en dos aspectos de las teorías del conocimiento al uso:

1) Será una teoría de las ciencias tanto como de las artes (humanidades). En lugar de ver las ciencias y las artes como dos dominios diferentes, presentará a ambos como partes diferentes de una y la misma empresa, del mismo modo que la física y la biología aún son vistas como partes de una y la misma empresa: la ciencia.

2) No contendrá reglas abstractas. Todas las reglas, las de la lógica incluida, quedarán vinculadas a un contexto bien especificado, y dará una razón histórica del contexto y del correspondiente uso de reglas (Feyerabend, 1977/2013: 302-303).

El presente artículo se concentra en exponer una dimensión fundamental de su nueva teoría de la ciencia, a saber, su dimensión humana. En primer lugar, se analizará la concepción que tiene el vienés de lo humano como criterio epistémico que debe definir el conocimiento científico (1). En segundo lugar, se presentará lo que Feyerabend reconoce como principio de Aristóteles, en la medida que este constituye para él un modo posible de resguardar la dimensión humana de la ciencia.

\section{LA DIMENSIÓN HUMANA DE LA CIENCIA}

No puede esbozarse el modelo positivo de ciencia formulado por Feyerabend si no se destaca lo humano como uno de los valores que la definen y distinguen. Lo humano -entendiendo por tal el contenido vivencial de una teoría o culturase erige como el valor epistémico según el cual Feyerabend evalúa y critica la supuesta superioridad de la ciencia frente a otras tradiciones de pensamiento. Su obra no solo es un ataque contra los intentos de establecer criterios de demarcación entre ciencia y no ciencia, sino también contra toda pretensión de establecer una línea de demarcación entre filosofía y el resto de la vida humana. Por tanto una hermenéutica que no atienda a su interés por hacer de la ciencia una empresa más culta y humana es incompleta:

La separación entre ciencia y filosofía de la ciencia es de hecho total. ¿Qué es lo que se puede hacer? Por lo que respecta al caso "ciencia" versus "filosofía de la ciencia", la receta es patente: necesitamos una filosofía que no se limite a hacer comentarios desde fuera, sino que participe en el proceso mismo de la ciencia. No debe haber ninguna línea de demarcación entre ciencia y filosofía. Tampoco deberíamos contentarnos con 
aumentar el contenido de verdad, el contenido empírico o cualquier otra cualidad. Comparadas con una vida plena y feliz estas cosas cuentan muy poco. Necesitamos una filosofía que dé a los hombres el poder y la motivación para hacer una ciencia más culta, en lugar de hacer una ciencia súper eficaz, súper verdadera, por un lado, pero tan bárbara, por otro, que degrada al hombre. Una filosofía así debe mostrar y probar todas las consecuencias de una existencia exigente, incluidas aquellas que no se pueden expresar por medio de palabras. Por eso no debe haber ninguna línea de demarcación entre filosofía y el resto de la vida humana (Feyerabend 1978/1993: 27).

Esta preocupación por el aspecto humano de la ciencia que hace eclosión a principios de los 80 fue una inquietud constante que puede rastrearse incluso en sus artículos publicados en los años $60^{3}$. La encontramos en la primera carta que Feyerabend dirige a Kuhn, datada por Hoyningen-Huene en mayo de 1961. Allí escribe a Kuhn que él se aventura en el estudio de una cuestión -como puede ser el principio de complementariedad de Bohr o un determinado descubrimiento científico- solo si de su solución depende el bienestar de la humanidad. Y por bienestar de la humanidad no quiere decir el bienestar físico, sino el bienestar en el cual se obtiene, entre otras cosas el completo desarrollo de las facultades humanas y la felicidad espiritual (Cf. Feyerabend 1961/2006: 613-614). En Consuelos para un especialista (1970) escribe: “¿Qué valores elegiremos para poner a prueba las ciencias de hoy? A mí me parece que la felicidad y el completo desarrollo del ser humano individual sigue siendo el valor más alto posible" (Feyerabend, 1970/1981b:143).

Feyerabend (1961/1999:69-70; 1970/1981b:143-144, 160-161) presenta las ventajas, metodológicas, cognoscitivas y éticas que se siguen de la adopción de un pluralismo epistemológico. En el ensayo Contra el método (1970/1989:148149) defiende un pluralismo metodológico como una posible vía para concretar una ciencia más humana. Afirma que la coexistencia en la ciencia de una pluralidad de concepciones del mundo que trasciendan incluso los límites del naturalismo cientificista es el único modo de poder medir las implicancias humanas de sus logros y resultados.

Parafraseando el ensayo de Mill sobre la Libertad humana define el bienestar como el desarrollo pleno de las facultades humanas (Cf. Feyerabend, 1961/1999:77; 1961/2006:613-614; 1965/1981:107; 1970/1981b:143; 1970/1989:157-158; 1975/1992:5-6 n. 12) ${ }^{4}$. Pues bien, la proliferación teórica en cuanto que garantiza

\footnotetext{
${ }^{3}$ Esta tesis se sostiene contra la opinión de Tula Molina (2005: 35 y ss.) quien interpreta la obra del vienés como la sustitución gradual de los ideales del positivismo por ideales humanistas.

${ }^{4}$ Denise Russell (1983: 451-452) partiendo de una malinterpretación del verdadero sentido de su anarquismo epistemológico sostiene que dada la defensa de Feyerabend del desarrollo de la libertad y de las facultades humanas como valores epistemológicos no puede concebirse su "todo vale" como un ultra-anarquismo.
} 
distintos estilos de vida y líneas de pensamiento diversas permite el desarrollo libre y sin restricciones del individuo (Cf. Feyerabend 1961/2006:143-144; 1970/1981a:65-67; 1970/1989:157-158). Este es para Feyerabend el objetivo primario de la ciencia y la razón por la cual considera que su valoración de la ciencia es más próxima a la de Mill que a la de Popper:

La diferencia entre Mill y Popper, no obstante, parece estar en esto. Para Mill el bienestar (material y espiritual) del individuo, el pleno desarrollo de sus capacidades, es el objetivo primario. El hecho de que los métodos empleados para conseguir este objetivo produzcan también una filosofía científica, un libro de reglas concernientes a la 'búsqueda de la verdad', es un efecto lateral, si bien agradable. Para Popper la búsqueda de la verdad parece ser mucho más importante, y ocupar un lugar más elevado que los intereses del individuo. En este punto mis simpatías están firmemente con Mill (Feyerabend, 1970/1989:154).

Mill no introduce la proliferación como un método para obtener nueva evidencia empírica, para facilitar el análisis lógico del lenguaje o para resolver el problema de Hume -explica Feyerabend (1970/1989:24; 1975/1992:161)-. Mill se plantea cómo es posible aumentar la libertad del hombre de tal modo que pueda decidir -más que adoptar por costumbre- el modo según el cual disponer de sus talentos. En este sentido, propone la proliferación como solución a un problema de vida o como respuesta a inquietudes específicas de la vida humana:

Hoy la única cuestión es cómo la ciencia puede mejorar sus propios recursos, sin importar cuál sea el efecto humano de sus métodos y sus resultados. Para Mill la conexión todavía existe. El método científico es parte de una teoría general del hombre. De esta teoría recibe sus reglas y se constituye de acuerdo con nuestras ideas de una existencia humana que merezca la pena (Feyerabend 1970/1989:25).

El proceder de la escuela popperiana -denuncia Feyerabend- es diametralmente inverso. Su objetivo primario no es hacer de la ciencia una empresa humana sino elaborar un método. Ésta surge como respuesta a las cuestiones metodológicas y epistemológicas que plantea el problema de la inducción de Hume y desde allí se generaliza una metodología o actitud crítica que debe regir no solo la ciencia sino a la política y conducta humana en general (Cf. Feyerabend 1978/1982:141; 1987/2005:64-65; 1996/1999:107-108). Tanto el racionalismo popperiano como la filosofía de la ciencia, en general, se limitan a ofrecer-según el vienés (1975/1992) - modelos matemáticamente descriptibles y empíricamente contrastables que nada dicen acerca de la relación del hombre respecto a la naturaleza. En ambos "las consideraciones humanistas están reducidas al mínimo" (176). 
En este sentido, sería más propio decir que el humanismo del vienés se inscribe en la filosofía de Mill ${ }^{5}$ y relativizar las afirmaciones de Oberheim (2006:9394) quien asegura que a pesar que Feyerabend adopta en los años 70 una actitud crítica respecto al racionalismo crítico, no deja de adoptar la actitud normativa de la ética -propia de la tradición popperiana- para juzgar la ciencia.

El pluralismo metodológico que formula en sus artículos tempranos solo puede ser entendido en el marco de esta preocupación por los efectos o implicancias que pueden tener en la existencia humana los métodos y resultados de la ciencia. De aquí que una descripción de su pluralismo teórico en términos estrictamente metodológicos y sin alusión alguna a esta intencionalidad o dimensión humana sería incompleta.

La invitación de Feyerabend (1989/2000) a recuperar la medicina herbaria, la acupuntura, la moxibustión y que "todos los sistemas médicos entren en libre y abierta competencia con la ciencia” (47) también debe ser entendida en el marco de su preocupación por hacer de la ciencia, una empresa más humana. En su Tratado contra el Método (1975/1992) escribe: "El pluralismo teórico y las concepciones metafísicas no son tan sólo importantes en metodología, sino que además forman parte esencial de una perspectiva humanista" (36).

Feyerabend (1989/2000) destaca la necesidad de examinar los supuestos y alcances de las teorías o prácticas clínicas pues "la eficacia de la medicina dependerá de la bondad de [estos] supuestos" (42). Ahora bien para medir y analizar críticamente las implicancias humanas y políticas de la medicina tradicional es preciso compararla con la acupuntura, la moxibustión y otros métodos de terapia y de diagnóstico para los cuales la medicina moderna no tiene ninguna explicación (Cf. Feyerabend, 1975/1992:34-35). Esto no supone una ingenua regresión a los estadios primitivos de la medicina tradicional, ni un desprecio a la larga tradición a través de la cual la medicina ha ido perfeccionándose. Por el contrario, con la proliferación Feyerabend (1989/2000) pretende ofrecer un método capaz de emprender una comparación sobre la calidad humana de los tratamientos convencionales y los alternativos; pues "sabemos lo que hace la moderna medicina científica, pero no sabemos si es lo mejor que se puede hacer. Ni siquiera sabemos si no es lo peor" (45) -explica- ${ }^{6}$.

El modo acrítico e ingenuo de los médicos de aceptar una determinada ontología, con la consideración explícita o implícita de que otras alternativas son simplemente no científicas es denunciada reiteradamente por Feyerabend; y alega que tanto los médicos clínicos, como aquellos que trabajan en un determinado

\footnotetext{
${ }^{5}$ Para un estudio crítico sobre el humanismo de Feyerabend como heredero de la filosofía Mill se puede ver Lloyd (2000: 122-123); Downes (2002: 163-164).

${ }^{6}$ Otras consideraciones análogas hace respecto a la economía (Cf. Feyerabend, 1996/1999:76-77).
} 
campo de investigación, parten de supuestos básicos acerca de la enfermedad, de la noción de calidad de vida, de técnicas y métodos diagnósticos que es preciso evaluar críticamente. Demuestra, por citar un ejemplo, la relevancia de la reflexión en torno a la noción de "calidad de vida" puesto que señala que de esta dependerá, por ejemplo, si se considerará o no a los ancianos como auténticos problemas médicos. Si por calidad de vida se entiende la ausencia de enfermedad y sufrimiento, entonces los ancianos estarían lejos de gozar una vida de calidad, y por tanto serían lícitos cuestionamientos tales como si vale la pena de prolongar este tipo de existencia. $\mathrm{Si}$, por el contrario, definimos la calidad de vida como la experiencia vivida desde determinados valores entonces la ancianidad se presenta en toda su dignidad y sentido. Feyerabend no quiere dar por resueltas estas discusiones. Simplemente pretende mostrar que según estas nociones de enfermedad, salud o calidad de vida, se determina qué es buena medicina y qué no lo es. En función de ellas se define el curso de la práctica médica y se decide financiar o no a determinadas investigaciones (Cf. Feyerabend 1989/2000: 22-23).

La proliferación teórica se presenta así como la posibilidad efectiva de construir una nueva ciencia que esté al servicio del hombre, es decir, una ciencia que a la hora de validar una teoría científica no atienda únicamente a parámetros metodológicos sino que exija un juicio y una elección prudencial acerca de las implicancias de sus supuestos políticos, económicos, antropológicos y éticos de la misma para la existencia humana (Cf. Feyerabend 1970/1981b:160-161; 1970/1989:120; 1975/1992:36-37; 253-254; 1996/1999:69-70). Para Feyerabend (1987/2005), "una decisión científica es una decisión existencial" (113). En este sentido, destaca el humanismo de Roberto Belarmino quien previendo que la precipitación de Galileo podía perturbar la fe del simple le exige al físico someter a debate y a pruebas matemáticas más precisas a su teoría (Cf. Feyerabend, 1975/1992: 180-181).

En La Ciencia en una Sociedad Libre (1978/1982:3-4, 29, 89-90, 117, 124, 149) Feyerabend intenta plasmar en la sociedad el ideal humanista de Mill, al mismo tiempo que juzga al racionalismo humanista de Popper como una versión desvirtuada de la filosofía de Mill. Lo acusa de ofrecer en La Sociedad Abierta y sus Enemigos (1945), una estructura formal que garantiza únicamente la primacía de la ciencia sobre las demás tradiciones sin atender a la felicidad y a la libertad individual que es -según Feyerabend- un rasgo característico de liberalismo de Mill. La consecuencia que tiene esta forma de proceder sobre la existencia humana y la vida en democracia no es sino la obstaculización del libre desarrollo de la humanidad:

El efecto es que los científicos y los racionalistas "liberales" han creado uno de los más funestos obstáculos para la democracia. Las democracias, tal y como la conciben los liberales, están siempre obstaculizadas por su lealtad conjunta a la racionalidad" (y esto 
hoy en día significa sobre todo: a la ciencia) y a la libertad de pensamiento y asociación. [...] Así es como una pequeña banda de supuestos "humanitaritas" ha logrado modelar la sociedad a su imagen y semejanza, y quitar de en medio a casi todas las formas de existencia. Habría sido una empresa encomiable si se hubiesen examinado atentamente las creencias que componen estas formas de vida (con el debido respeto para quienes participan de las mismas) y se hubiese descubierto que son un obstáculo para el libre desarrollo de la humanidad (Feyerabend 1978/1982:158-159).

El vienés se esfuerza por superar la dialéctica objetivismo-relativismo. Para el objetivismo la naturaleza de las cosas puede determinarse en virtud de un marco permanente y universal de pensamiento. Para el relativismo, en cambio, todos los conceptos o sistemas de pensamiento son relativos a un marco sociohistórico determinado. Ni uno ni el otro explica Feyerabend pueden dar razón de la comunicación e interacción entre las cultura, ni de la abundancia de lo real. De aquí la necesidad de abandonar o trascender la dicotomía relativismo/absolutismo.

Feyerabend (1975/1999:190-191; 1978/1982:100; 1978/1993:182$184 ; 1980 / 1999: 215 ; 1987 / 2005: 66,78-80)$ propone una sociedad donde cada ciudadano juzgue la ciencia y las demás tradiciones según el estilo de vida que quiere llevar. La convivencia pacífica de las distintas tradiciones y el progreso científico constituyen para él algo positivo en la medida que son puestas a servicio del hombre y de la felicidad individual de cada uno de los ciudadanos.

En la edición del 75 de su Tratado contra el Método dedica tres capítulos para desarrollar un estudio antropológico sobre las implicancias que se siguen para la existencia humana de los criterios o supuestos cosmológicos propios de ciertos episodios de la historia de la ciencia:

Hacia el final del capítulo 17 que es este estudio de casos concretos -más que los áridos ejercicios de los racionalistas- defiendo que lo que debe guiar a un científico es un estudio antropológico (a la vez que me opongo a un estudio lógico) de los criterios. En los capítulos 2, 12 y 17 muestro cómo y porqué la estructura del conocimiento y las leyes del desarrollo humano, en conexión con unos sencillos supuestos cosmológicos, favorecen un enfoque histórico-antropológico (Feyerabend 1978/1982: 223).

Como resultado de este estudio antropológico de la ciencia Feyerabend (1991b) descubre que "El conocimiento tal como lo definen los racionalistas: un conocimiento objetivo desprovisto de toda emoción, cuyos ingredientes pueden expresarse, sin excepción, en enunciados precisos, no es el único tipo de conocimiento, ni siquiera en las ciencias" (88-89). En la posibilidad de establecer un diálogo e interacción con otras culturas, encuentra un modo de poder juzgar en perspectiva los logros del materialismo cientificista y de redirigir la ciencia 
hacia una visión más armónica del universo (Cf. Feyerabend, 1987/2005:14). Su preocupación por la dimensión humana de la ciencia es el trasfondo que justifica la invitación que hace en Adiós a la Razón (1987) de retomar las ideas más modestas pero también más abiertas y amplias que ofrecen las visiones religiosas del mundo, la ciencia de la antigua Grecia y la ciencia medieval.

La religión es vista por Feyerabend como una de las posibles alternativas para infundir sentido y humanidad a la ciencia. La unión entre ciencia y religión no la concibe como un problema de consistencia que debe ser resuelto teóricamente. Le interesa destacar, sobre todo, la armonía que adquiere la ciencia en la entera existencia humana cuando aquella unidad se concreta. Por la religión la ciencia es puesta al servicio del hombre, como en el caso de la astronomía y la aritmética de Pitágoras que no eran valoradas como un bien en sí mismo sino que constituían un medio para purificar y salvar el alma (Cf. Feyerabend, 1996/1999:110-114). Por las visiones religiosas del mundo la ciencia adquiere -según Feyerabend (1991/2003:127) - una dimensión que trasciende los valores de utilidad y eficacia ${ }^{7}$. Ellas confieren sentido a los resultados científicos dentro de una imagen del mundo que implica a la persona como un todo. El naturalismo cientificista, en cambio, "sólo proporciona una parte de lo necesario para para una vida completa [pues] afirmar que no existe nada más [que la materia] vacía el mundo de sentido" (Feyerabend, 1991/2003:116) -escribe. En Ambigüedad y Armonía describe las consecuencias que se siguen de la dialéctica que instaura la modernidad entre la ciencia y la religión del siguiente modo:

Es verdad que la religión habla sobre el alma, los propósitos y sentidos. No sólo esto, la religión también crea sentido en lugares que a primera vista parecen desprovistos de él. Pero hoy, y en Occidente, la práctica de ideas religiosas y rituales está estrictamente limitada. El creyente está dividido en una parte que actúa "como científico" y otra que actúa, digamos, "como cristiano". "Como científico" enuncia a la fe y a la revelación y deja de lado los sentidos. "Como cristiano" se apoya en la fe y sigue los designios divinos. No existe modo de infundir espíritu religioso en la ciencia. La religión es algo añadido después de que la ciencia ha hecho su trabajo, no es parte de dicho trabajo (Feyerabend, 1996/1999:38-39).

Por otro lado, la ciencia de la antigüedad griega se le manifiesta a Feyerabend (1978/1982:70; 1991a:114) como un conocimiento complejo acerca de la naturaleza que resguardaba la libertad y la integridad del hombre. Para el griego -explica el vienés- cualquier ocupación, arte o ciencia que haga al cuerpo o al alma menos apta para el ejercicio de la virtud, es vulgar. La ciencia debe adaptarse a los requerimientos de una vida plena y equilibrada. Aún más, la educación griega entendía que algunas

\footnotetext{
${ }^{7}$ Nickels (1998:128-132) expone importantes consideraciones respecto al interés de Feyerabend
} por hacer de la ciencia una empresa filosófica que trascienda los valores de utilidad y eficiencia. 
formas de conocimiento son adecuadas para el hombre libre hasta cierto punto pues si este les dedica excesiva atención ellas le provocaran un efecto pernicioso (Cf. Feyerabend, 1994/1999:255; (1996/1999:45). Esta sabiduría griega es la que Feyerabend (1978/1982) contrapone a "la aproximación científica a la realidad [que] sólo busca la eficacia y la suficiencia teórica sin importarle en absoluto el dañó espiritual que pueda ocasionar a los hombres" $(210)^{8}$.

En Diálogos sobre el conocimiento (1991) sostiene que el griego expone su filosofía en forma de diálogo para expresar con ello el drama existencial que implica el conocimiento. Cita a Sócrates y a Teeteto como arquetipos de una filosofía y una matemática con una dimensión existencial que les ofrecía un sentido por el que vivir y por el cual estaban también dispuestos a morir. Esta es la dimensión existencial que Feyerabend denuncia estar ausente en los análisis lógicos del lenguaje:

En segundo lugar, hay una "dimensión existencial”, por llamarla de algún modo; la forma en que toda la conversación se inscribe en situaciones extremas de la vida real. Presiento que todo esto queda muy lejos de esas numerosas secciones de la filosofía moderna donde sólo analizamos las propiedades lógicas de los conceptos y creemos que eso es todo cuanto se puede decir sobre ellos (Feyerabend, 1991b:20).

La ciencia medieval subordinada a la comprensión de los misterios teológicos también se le presenta a Feyerabend como una empresa cognoscitiva más humana que la que ofrece la ciencia moderna. Para esta última la ciencia es valiosa por sí y en sí misma, siendo incapaz de ordenarse a fines más amplios capaces de dar sentido a la existencia humana:

En los últimos años he descubierto que esta actitud mía no es precisamente un capricho personal, sino que ha sido y sigue siendo compartida por muchas tradiciones. Los medievales investigaban en campos estrechos, pero también eran fieles miembros de la Iglesia. Pertenecían a la comunidad de eruditos, pero también eran miembros potenciales de la comunidad de los santos y eran conscientes de ello. Esta consciencia, les impedía obtener, de una empresa limitada, estrecha e históricamente accidental, una medida de la humanidad en su conjunto. [...] La ciencia, en ambos casos, no es importante por sí y en sí misma. No tiene importancia independiente; recibe su substancia como parte de una vida dedicada a materias incomparablemente más importantes. Un ser humano no puede ser un científico, pero él, o ella, es sólo un verdadero científico si es consciente de esos asuntos más amplios. $\mathrm{O}$, dicho con las palabas de Einstein, la grandeza de un científico consiste en que él permanece cuando se le sustrae su ciencia.

\footnotetext{
${ }^{8}$ Las conclusiones que infiere de este diálogo con la antigua Grecia, particularmente con Aristóteles, se exponen en el siguiente punto.
} 
El surgimiento de la ciencia moderna ha eliminado tales mecanismos compensadores y los ha remplazado por una "filosofía" materialista estrecha (a veces también llamada "humanística" (Feyerabend, 1987/2005:98-99).

"Una visión del mundo -escribe- no es precisamente un lujo intelectual, [...] es por el contrario, una respuesta muy necesaria a los problemas más acuciantes de nuestro tiempo" (Feyerabend, 1994/1999:210-211). Una visión del mundo proporciona al hombre un sentido por el cual vivir. Incluso la ciencia moderna en sus orígenes, es decir, tal cual esta fue practicada por Newton y Kepler representa para Feyerabend una dimensión más humana que la ciencia actual en la medida que aquella tiene la potencialidad de dar respuesta a los interrogantes del hombre acerca del origen y el fin de su existencia:

Las visiones del mundo también responden a preguntas que más tarde o más temprano surgen en todo ser humano sobre los orígenes y los fines. Las respuestas a estas preguntas estuvieron al alcance de Newton y Kepler y fueron utilizadas por ellos en su investigación. Hoy ya no están al alcance, al menos no dentro de las ciencias. Forman parte de las visiones del mundo no científicas que por lo tanto tienen mucho que ofrecer, también a los científicos (Feyerabend, 1994/1999:190).

Pero el largo derrotero de la ciencia moderna culmina en una empresa que con pretensión de autosuficiencia relega las visiones del mundo capaces de satisfacer los interrogantes más propios del hombre al campo de las humanidades. Los resultados de la ciencia proporcionan un conocimiento del tipo predictivo de un sector de la realidad pero carecen de lo que Evandro Agazzi (1978) entiende como "conferimiento de sentido" (62-66). Citando las palabras del biólogo molecular Jacques Monod, Feyerabend (1994/1999) describe la ciencia actual como una "búsqueda ansiosa de sentido en un universo helado de soledad" (26). El modelo racionalista de ciencia no es sino el resultado de una larga tradición que en aras de alcanzar un conocimiento objetivo impone una "renuncia ascética de todo alimento espiritual" (26) y, por tanto, cierra toda posibilidad de hacer de la ciencia una empresa más humana. Esta es una de las tesis presentes a lo largo de toda su Conquista de la Abundancia (1994).

A través del lenguaje metafísico y antropomórfico que Feyerabend adopta en esta obra, sobre todo sus referencias en torno a la aprobación o resistencia del Ser, destaca la necesidad de atender a la calidad de vida que proponen las culturas a sus miembros. El Ser o la naturaleza aprueba las culturas en la medida que ellas proporcionan a sus miembros una vida buena y plena, pero se resiste a aquellas que no la ofrecen. Aunque también es lo "suficientemente complejo como para burlarse y, quizá, castigar a los materialistas respondiéndoles de una forma groseramente materialista" (Feyerabend, 
1991/2003:150-151). Su metafísica revela cómo las culturas con sus consecuentes estilos de vida participan de la complejidad y abundancia del mundo:

Muchas tradiciones y culturas, algunas de ellas extraordinariamente "acientíficas" (se dirigen a las divinidades, consultan oráculos, realizan ritos "sin sentido" para perfeccionar el cuerpo y el alma) han tenido éxito en el sentido de hacer posible que sus integrantes lleven una vida moderadamente rica y plena. Aplicando el criterio amplio del éxito, llego a la conclusión de que también las nociones no científicas reciben una respuesta de la naturaleza, que la naturaleza es más compleja que lo que sugeriría una creencia en la uniformidad y la excelencia exclusiva de la ciencia y que una tarea interesante para un escritor capaz de trascender los límites de una escuela particular sería considerar algunas de sus propiedades (Feyerabend, 1994/1999:232).

El valor humano se erige para Feyerabend como el criterio de éxito de las culturas. Luego el progreso científico -que particularmente parece haber alterado el equilibrio del hombre con la naturaleza que se había alcanzado en épocas anteriores- debe ser juzgado por las implicancias que se siguen de ella para la existencia humana. Erigir los valores espirituales o el conferimiento de sentido no es abogar por la irracionalidad o la mera subjetividad como sostiene Preston (1997:210; 2000:90-91). Valorar la humanidad de la ciencia por la vida buena y plena que ofrece una tradición, excede evidentemente los criterios de veracidad o validez de cualquier racionalista; y es que Feyerabend parece entrever la identidad metafísica entre verdad y bien, entre ciencia y felicidad que fue olvidada y abandonada paulatinamente en las nociones modernas de método, ciencia y objetividad.

\section{LA DIMENSIÓN HUMANA DEL PRINCIPIO DE ARISTÓTELES}

Feyerabend destaca recurrentemente a Aristóteles como aquel pensador que ofrece recursos valiosos para superar las escisiones o dialécticas propias del racionalismo científico. Entre los pasajes más representativos se puede citar el sexto capítulo de su Filosofía Natural (1970/2013:223-279) titulado "La filosofía natural occidental de Aristóteles a Bohr" donde pone de relieve las ventajas que presenta la concepción aristotélica de ciencia respecto al abordaje matemático de la naturaleza de Descartes. También en La Ciencia en una Sociedad Libre (1978/1982:55-71) dedica un apartado denominado "Aristóteles no ha muerto" a exponer la doctrina aristotélica del conocimiento como una posible vía para recuperar la unidad existente entre las acciones prácticas del científico y sus consideraciones teóricas1. Finalmente en su obra póstuma, La Conquista de la Abundancia (1994/1999:255- 
262) bajo el título de "Aristóteles" dedica un capítulo a analizar las respuestas que da el Estagirita al idealismo platónico y a la doctrina de Parménides.

Pero lo que nos interesa analizar aquí es lo que Feyerabend designa como principio de Aristóteles en la medida que éste le ofrece una orientación a su preocupación por la dimensión humana de la ciencia.

En el manuscrito inconcluso que constituye su Conquista de Abundancia (1994) presenta tal principio como aquel criterio que permite juzgar las entidades y teorías científicas según si el mundo a que dan lugar es placentero o no para vivir. Define lo real como "aquello que tiene un papel importante en el tipo de vida que uno quiere vivir" (Feyerabend, 1994/1999:292. Cf. 1981:13-14; 1991b:53, 8789, 123-125; 1994/1999:33, 96, 255). Las vidas humanas, en el pleno sentido de la palabra, tienen lugar en el mundo real, luego -arguye Feyerabend- no puede ser considerado como una quimera aquello que desempeńa un papel importante en ellas (Cf. Feyerabend, 1991/2003:61-62, 70-71; 1994/2000:166-167).

Feyerabend (1994/1999) escribe que "la ciencia humana se debe adaptar a los requerimientos de una vida plena y equilibrada" (255). Y a continuación agrega que "según Aristóteles, estos requerimientos también definían su contenido"(255). Aristóteles al señalar contra Parménides que las cosas naturales, es decir, las cosas que conforman la vida de los hombres están sometidas al cambio sitúa la vivencia, concretamente, el estado de vigilia de un hombre sano en medida de verdad y realdad (Cf. 256). Continuando con este razonamiento de Feyerabend se puede decir que al erigir la existencia o la vivencia como medida de la realidad, Aristóteles también establecería concomitantemente la felicidad y la vida buena y plena como criterio de verdad. De aquí que el principio de Aristóteles -tal como lo formula nuestro epistemólogo- exige que los resultados científicos sean beneficiosos para el individuo y la sociedad antes de convertirlos en medida de la realidad.

En el capítulo que lleva por título el nombre del filósofo griego, Feyerabend analiza aquel pasaje de la Ética a Nicómaco (1096b:33 y ss.) donde el Estagirita se pregunta irónicamente por la utilidad que brindaría la idea platónica de Bien, esta no puede ser producida ni adquirida por los seres humanos:

[...] pues si el bien predicado en común de varias cosas es realmente uno, o algo separado que existe por sí mismo el hombre no podría realizarlo ni adquirirlo; $y$ lo que buscamos ahora es algo de esta naturaleza.

... Además no es fácil ver qué provecho sacarán por su arte el tejedor o el carpintero de no conocer el bien en sí, o cómo podría ser mejor médico o mejor, en general, aquel que haya contemplado esta Idea. Es evidente que el médico no considera así la salud, sino la salud del hombre o, más bien aún, la de este hombre, ya que cura a cada individuo (Aristóteles en Feyerabend, 1994/1999: 256. Las cursivas son de Feyerabend). 
En este pasaje se manifiesta -según Feyerabend (1994/1999:94-95) - el interés de Aristóteles por formular una teoría del conocimiento y un criterio de realidad que acerque el conocimiento a las vivencias humanas. Es decir su intención de elaborar una ciencia que represente un bien para el hombre y que esté al servicio de él y no a la inversa. Pues si la realidad debe juzgarse de acuerdo a la experiencia y el sentido común de los hombres, entonces Aristóteles está demostrando que el uso e interpretación de los resultados científicos es una cuestión política pues esta tiene que ver con la vida de la gente tal y como esta se expresa en sus experiencias diversas y en el sentido común. Luego -concluye nuestro filósofo de la ciencia- la realidad "no se puede dejar en manos de los especialistas" (258), es decir, en manos de los científicos:

El análisis de Aristóteles deja claro en último caso nos enfrentamos a decisiones políticas que se sobreponen a los argumentos científicos. El respeto absoluto a los especialistas tiende a desdibujar la distinción entre los elementos políticos (o sociales, cuando la decisión se produce de forma automática) y los científicos de nuestras nociones de realidad. Somos propensos a creer que los dictámenes de los especialistas son conocimiento del tipo más puro, sin nada añadido. Un estudio de Aristóteles, asistido tal vez de un estudio de la exposición de Duhem, restituye la claridad y devuelve a los ciudadanos el poder al que antes han renunciado por error (Feyerabend, 1994/1999:258).

El principio de Aristóteles limita la ciencia al someterla a la tradición y al estilo de vida que el individuo o una sociedad decide adoptar (Cf. Feyerabend, 1981:13-14). Pues en cuanto que dicho principio hace depender lo real de la tradición que el hombre elija, la ciencia queda supeditada a una decisión ética. Por ética, Feyerabend (1994/1999) entiende aquella decisión individual de asumir un determinado tipo de vida y, por tanto, un modo particular de entender y vivenciar el mundo. En este sentido escribe que la ética debe convertirse en "juez público" (291) de la ciencia. "[L]a ética (en el sentido general de una disciplina que guía nuestras elecciones entre formas de vida) afecta a la ontología" (Feyerabend, 1991/2003:70). Tal conclusión Feyerabend la recoge y expone en su artículo La ética como medida de la verdad cientifica (1992):

Una primera y bastante inmediata consecuencia [del principio de Aristóteles] es que la línea divisoria entre la realidad y la apariencia no puede ser establecida mediante la investigación científica, porque contiene un componente normativo o, si lo prefieren, "existencial".

Esto explica, en segundo lugar, por qué tantos procesos distintos (visiones, experiencia inmediata, sueños y fantasías religiosas) han sido declaradas reales y por qué las discusiones en torno a la realidad son tan acaloradas. Después de todo, 
se trata de debates sobre el modo correcto de vivir o, en ámbitos más restringidos sobre el modo correcto de hacer investigación. Llegan a un acuerdo sobre el peso que debemos dar a la razón, la experiencia, la emoción, la fe, la fascinación y otros entes que en algunas teorías están estrictamente separados, mientras que en otras aparecen mezclados (Feyerabend, 1991/2003:80).

Toda teoría, toda tradición o cultura posee una noción metafísica de realidad que trasciende el conjunto de datos científicos que disponen a su favor. Estas nociones metafísicas de realidad se definen en virtud de un componente ético normativo que en la ciencia o en la visión científica del mundo también se ha planteado aunque subrepticiamente y sin discusión. Feyerabend (1991/2003) propone iniciar un debate sobre las implicancias éticas y humanas de las tradiciones y culturas introduciendo nuevas maneras de definir lo real o de discriminar metafísicamente lo real respecto a lo aparente. De este modo, el contenido ético implícito en sus distintos criterios de realidad es juzgado abiertamente por la ética. "Podemos decir que la ética, habiendo sido una vez la medida secreta de la verdad científica, puede ahora convertirse abiertamente en su juez" (71).

La ciencia debe estar sometida a la ética y no a la inversa. Pero Feyerabend se opone a todo intento de concebir la ética como un sistema a priori de normas universales inferidas de la ciencia. Esta no puede ser entendida como la universalización o explicitación de los valores implícitos en la visión científica del mundo. Y, por tanto, una cultura o tradición no puede ser juzgada por lo ideales propios del racionalismo cientificista. Concretamente, el nivel de vida que las tradiciones ofrecen a sus miembros no puede ser evaluada en función del producto nacional bruto, de la esperanza de vida o del nivel de alfabetización. Es, decir, no se puede medir su calidad de vida desde los valores de la cultura occidental. En este sentido afirma que no se puede argumentar desde la realidad científica hacia la ética y los derechos humanos:

Según Fang, argumentamos desde la realidad científica hacia la ética y los derechos humanos. Este es un movimiento peligroso. Usa normas, pero las esconde tras enunciados factuales, elimina nuestras elecciones e impone leyes en lugar de dejar que maduren a partir de la vida de sus supuestos beneficiarios. Yo sugiero que argumentemos al revés, desde el tipo de vida "subjetivo", "irracional" e idiosincrásico que somos, en sintonía con lo que va ser considerado real. La inversión tiene muchas ventajas. Está de acuerdo con los derechos humanos. Nos hace tomar conciencia del hecho de que la "realidad" de Fang es el resultado de una elección y puede ser modificada: no estamos obligados a mantenernos fieles al "progreso" y a la "universalidad" (Feyerabend, 1991/2003: 74). 
Feyerabend invierte el habitual cuestionamiento cientificista sobre las implicancias éticas de la ciencia. Este se pregunta por las consecuencias que se siguen de una única realidad científica mientras que supone que todas aquellas tradiciones o culturas que tienen creencias y ontologías no científicas vive en una ilusión. Nuestro epistemólogo (1991/2003), en cambio, asegura que la ética debe ser el criterio ontológico que defina lo real. Las tradiciones con sus respectivas nociones de realidad deben ser juzgadas desde interrogantes éticos, tales como, "¿Son realmente meros sueños, o hay en ellas felicidad, perspicacia, comprensión, afecto y un crecimiento gradual desde la infancia, pasando por la adolescencia, hasta la madurez y vejez? ¿Hay una actitud generosa hacia los demás más allá de las intenciones?" (71). Lo real, de este modo es establecido conforme a aquello que proporciona a los hombres una vida feliz y plena en tanto despliega las facultades humanas.

Esto no supone, por parte de Feyerabend un desprecio de la ciencia, sino el deseo de que esta recupere su dimensión humana supeditándose al juicio, a la libertad y a la dignidad del hombre.

En la introducción que escribe para el volumen I de sus Philosophical Papers: Introduction: Scientific Realism and Philosophical Realism (1981), Feyerabend no solo hace explícita su decisión de asumir el principio de Aristóteles como criterio ético-ontológico sino que también denuncia el fracaso de la filosofía de la ciencia por definir éticamente la realidad científica en cuanto que las decisiones éticas o políticas sobre la realidad trascienden sus metodologías y parámetros de racionalidad científica:

¿Debemos nosotros preferir afirmar la realidad de nuestras visiones comunes sobre la realidad de las concepciones de algunos especialistas? [...] Estas [preguntas] involucran tanto la elección entre formas de vida y la adaptación de nuestras ideas y hábitos de ideas (percepción, intuición) a la tradición elegida: nosotros decidimos estimar como reales aquellas cosas que juegan un papel importante en la forma de vida que preferimos.

[...] Esto también está mostrando que los filósofos de la ciencia quienes trataron de entender y domesticar la ciencia con la ayuda de estándares y metodologías que trascienden la investigación, han fallado (vol. 2, cap. 9, 10, 11; cf. vol. 2, cap. $1.5 \mathrm{f} \mathrm{y}$ parte I de SFS): una de las más importantes e influenciables instituciones está más allá del alcance de la razón como es interpretado por la mayoría de los racionalistas contemporáneos. El fracaso no pone fin a nuestros intentos de adaptar la ciencia a nuestras formas de vida preferidas. Todo lo contrario: esto libera el intento de restricciones irrelevantes. Esto está en perfecto acuerdo con la filosofía Aristotélica la cual también limita la ciencia por la referencia al sentido común excepto aquella concepción de un filósofo individual (Aristóteles) son ahora remplazadas por decisiones políticas emergentes de instituciones de una sociedad libre (vol. 2, ch. 1.7) (Feyerabend, 1981:xiii-xiv). 
Tal como lo explicita la cita, muchos de sus artículos deben ser leídos como un intento por formular positivamente una noción de realidad que resguarde la dimensión humana del conocimiento. De algún modo, Aristóteles logra formular el modelo de ciencia que Feyerabend persigue en sus últimos obras, el cual es caracterizado por su esposa Grazia Borrini (1999:14), como aquel que no reduce la riqueza y complejidad del ser y que sostiene pero nunca degrada la vida que tiene sentido para el hombre 9 . El mismo Feyerabend lo reconoce cuando escribe:

De cualquier modo que enfoquemos una determinada materia podemos aprender mucho de Aristóteles respecto al conocimiento, la investigación y las implicancias sociales de ambos. Hoy en día, cuando más del 30\% de todos los científicos trabajan en proyectos relacionados con la guerra, cuando se da por sentado que la investigación sobre materias recónditas se debe financiar con dinero público y cuando la existencia y la naturaleza humana se degradan para que se adapten a las modas científicas más recientes, su idea de que la interpretación y el empleo de la ciencia son un asunto político es más actual que nunca (Feyerabend, 1994/1999:261).

\section{CONCLUSIÓN}

El pensamiento de Feyerabend no puede ser simplemente entendido en el marco de escepticismo o como una mera radicalización de las consecuencias absurdas que se siguen de los supuestos de sus interlocutores. Feyerabend también esboza aunque habitualmente de un modo implícito, una teoría positiva acerca de la ciencia. A través de una ampliación temática y metodológica procura acceder a una comprensión de la ciencia desde una perspectiva más comprehensiva.

Desde esta nueva perspectiva la ciencia es juzgada y valorada por una racionalidad que procura atender a su contenido humano y vivencial.

Quizás podríamos vernos tentados a calificar, prematuramente, como pragmática, ambigua o excesivamente subjetiva esta solución de nuestro epistemólogo. Definir lo real por la vida buena plena que ofrece una tradición, excede evidentemente los criterios de veracidad, validez o cientificidad de cualquier racionalista.

Pero pensemos una segunda alternativa. Consideremos la posibilidad de que Feyerabend no está escapando al problema de humanizar la ciencia con una solución pragmática sino que entrevé la identidad metafísica entre verdad y bien, entre ciencia y felicidad que fue olvidada y abandonada paulatinamente en nuestras nociones modernas de método, ciencia y objetividad.

\footnotetext{
${ }^{9}$ Feyerabend (1991/2003: 82-83, 158) reconoce explícitamente una continuidad entre su metafísica
} de la abundancia y el principio de Aristóteles. 


\section{REFERENCIAS}

Agazzi, Evandro. Temas y problemas de Filosofía de la Física. Barcelona: Herder, 1978.

Borrini, Grazia. "Prefacio y Reconocimientos". La Conquista de la Abundancia. La abstracción frente a la riqueza del ser. Barcelona: Paidós, 1999.

Downes, Stephen. "Review of Conquest of Abundance: A Tale of Abstraction versus the Richness of Being, By Paul Feyerabend; and of The Worst Enemy of Science?" In John Preston, Gonzalo Munévar and David Lamb (Eds.). Essays in memory of Paul Feyerabend. Science, Technology \& Human Values 27. New York: Oxford University Press, (2002): 160-164.

Feyerabend, Paul. “Knowledge without foundation.” In John Preston (Ed.). PaulK. Feyerabend: Knowledge, Science and Relativism, Philosophical Papers Volume 3, Cambridge: Cambridge University Press, (1961/1999): 50-77.

Feyerabend, Paul. "More letters by Paul Feyerabend to Thomas S. Kuhn on Proto Structure." In Paul Hoyningen-Huene (Ed.). Studies in History and Philosophy of Science 37, (1961/2006): 610-632.

Feyerabend, Paul. "Reply to Criticism. Comments on Smart, Sellars and Putnam.” In Realism, rationalism and scientific method, Philosophical Papers Volume 1. Cambridge: Cambridge University Press, (1965/1981): 104-131.

Feyerabend, Paul. "Two Models of Epistemic Change: Mill and Hegel”. Problems of Empiricism. Philosophical Papers Volume 2. Cambridge: Cambridge University Press (1970/1981a): 65-79.

Feyerabend, Paul. "Consolations for the Specialist". Problems of Empiricism. Philosophical Papers Volume 2. Cambridge: Cambridge University Press, (1970/1981b): 131-167.

Feyerabend, Paul. Contra el Método. Esquema de una Teoría Anarquista del Conocimiento. Barcelona: Ariel, 1970/1989.

Feyerabend, Paul. Filosofía Natural. Buenos Aires: Debate, 1970/2013.

Feyerabend, Paul. Tratado contra el Método. Esquema de una Teoría Anarquista del Conocimiento. Madrid: Tecnos, 1975/1992. 
Feyerabend, Paul. "How to Defend Society Against Science." In John Preston (Ed.). Paul K. Feyerabend: Knowledge, Science and Relativism, Philosophical Papers Volume 3. Cambridge: Cambridge University Press (1975/1999): 181-191.

Feyerabend, Paul. "Solicitud de un Año Sabático". Filosofía Natural. Buenos Aires: Debate, (1977/2013): 295-310.

Feyerabend, Paul. La Ciencia en una Sociedad Libre. Madrid: Veintiuno Editores, $1978 / 1982$.

Feyerabend, Paul. ¿Por qué no Platón? Madrid: Tecnos, 1978/1993.

Feyerabend, Paul. "Democracy, Elitism and Scientific Method". In John Preston (Ed.). Paul K. Feyerabend: Knowledge, Science and Relativism, Philosophical Papers Volume 3. Cambridge: Cambridge University Press, (1980/1999): 212-226.

Feyerabend, Paul. "Introduction: Scientific Realism and Philosophical Realism." Realism, rationalism and scientific method, Philosophical Papers Volume 1. Cambridge: Cambridge University Press, (1981): 3-16.

Feyerabend, Paul. Adiós a la Razón, Tercera edición. Madrid: Tecnos, 1987/2005.

Feyerabend, Paul. Diálogos sobreel Método. 2a edición. Madrid: Cátedra, 1989/2000.

Feyerabend, Paul. Provocaciones Filosóficas. Madrid: Editorial Biblioteca Nueva, $1991 / 2003$.

Feyerabend, Paul. Three Dialogues on Knowledge. Cambridge: Basil Blackwell, 1991a.

Feyerabend, Paul. Diálogos sobre el conocimiento. Madrid: Cátedra, 1991b.

Feyerabend, Paul. "Concluding Unphilosophical Conversation." In Gonzalo Munévar G. (Ed.). Beyond Reason: Essays on the Philosophy of Paul Feyerabend. Boston Studies in the Philosophy of Science, Volume 132. Dordrecht: Kluwer, (1991c): 487-527.

Feyerabend, Paul. La Conquista de la Abundancia. La abstracción frente a la riqueza del ser. Barcelona: Paidós, 1994/1999. 
Feyerabend, P. "Paul Feyerabend: Last Interview." In John Preston, Gonzalo Munévar and David Lamb (Eds.). By Jung J. The Worst Enemy of Science? Essays in memory of Paul Feyerabend. New York: Oxford University Press, (1994/2000): 159-168.

Feyerabend, Paul. Ambigüedad y Armonía. Barcelona: Paidós, 1996/1999b.

Hooker, Cliff. "Between Formalism and Anarchism: A Reasonable Middle Way". Beyond Reason. Essays on the Philosophy of Paul Feyerabend. In Gonzalo Munévar (Ed.). Dordrecht: Kluwer Academic Publishers, (1991): 41-107.

Lloyd, Elisabeth. "Feyerabend, Mill, and Pluralism." The Worst Enemy of Science? Essays in memory of Paul Feyerabend. In John Preston, Gonzalo Munévar and David Lamb (Eds.). New York: Oxford University Press, (2000): 115124.

Musgrave, Alan. "Evidential Support, Falsification, Heuristics, and Anarchism". In Gerard Radnitzky and Gunnar Andersson (Eds.). Progress and Rationality in Science. Dordrecht, Holland: D. Reidel Publishing Company, (1978): 181-201.

Neto, Maia. "Evidential Support, Falsification, Heuristics, and Anarchism", Studies in History and Philosophy of Science 22 (1991): 543-555.

Toledo, Ulises. "La Epistemología según Feyerabend", Cinta de Moebio 4 (1998): 123-129.

Oberheim, Eric. Feyerabend's Philosophy. Quellen Und Studien Zur Philosophie. Berlín: Walter de Gruyter, 2006.

Preston, John. Feyerabend. Philosophy, Science and Society. Oxford: Blackwell, 1997.

Preston, John. “Science as Supermarket: 'Post-Modern' Themes in Paul Feyerabend's Later Philosophy of Science”. In John Preston, Gonzalo Munévar and David Lamb (Eds.). The Worst Enemy of Science? Essays in memory of Paul Feyerabend. New York: Oxford University Press, (2000): 80-101.

Russell, Denise. “Anything Goes”, Social Studies of Science 13 (1983): 437-364. 
Tula Molina, Fernando. "Ideales de conocimiento y Problemas Epistemológicos: El caso del Realismo Feyerabendiano". En María Cristina Di Gregori y María Aurelia Di Berardino (Comps.). Conocimiento, realidady relativismo. México: UNAM, (2006): 26-40. 